\title{
Geographic Human-Computer Interaction
}

Brent Hecht

Northwestern University

EECS Department

Evanston, Illinois, USA

brent@u.northwestern.edu

\section{Johannes Schöning}

German Research Center for Artificial Intelligence

66123 Saarbrücken, Germany

schoening@dfki.de

\section{Thomas Erickson}

IBM T.J. Watson Research Center

Yorktown Heights, New York, USA

snowfall@acm.org

\section{Reid Priedhorsky}

IBM T.J. Watson Research Center

Cambridge, Massachusetts, USA

reid@reidster.net

Copyright is held by the author/owner(s).

CHI 2011, May 7-12, 2011, Vancouver, British Columbia, Canada ACM 978-1-60558-930-5/10/04.

\begin{abstract}
Researchers and practitioners in human-computer interaction are increasingly taking geographic approaches to their work. Whether designing novel location-based systems, developing natural user interfaces for maps, or exploring online interactions over space and time, $\mathrm{HCI}$ is discovering that geographic questions, methods, and use cases are becoming integral to our field. Unfortunately, to our knowledge, there have been no direct efforts to unite members of the community exploring geographic HCI. The goal of this forum is to bring together researchers from a variety of areas to provide a summary of what has been done thus far and to discuss options for developing a more formal geographic HCI community. We will also highlight the troublesome lack of communication between scholars in geography and $\mathrm{HCI}$ and the opportunities that will result from increased collaboration between the two fields.
\end{abstract}

\section{Keywords}

geography, location, maps, location-based systems (LBS), GPS, distance, geo, spatio-temporal

\section{Introduction}

Prior to the turn of the century, the use of computerbased geographic technologies remained largely limited 
to a select group of spatial experts in the sciences, engineering, and the military. The rapid advancement of geographic technologies over the past fifteen years however, has resulted in a vastly increased audience. These novel technologies, their huge user base, and the shifting practices of this base have attracted the attention of $\mathrm{HCI}$ researchers and practitioners. In the HCI literature, geographic approaches have been taken by researchers interested in such disparate areas as natural user interfaces, social computing, mobile computing, social network analysis, and disaster response. Yet, of the $100+$ keywords in the SIGCHI reviewing system, there is no instance of "map," "geographic," or "geo"-anything. In light of this, perhaps it is not so surprising that there has never been an attempt to share knowledge amongst those interested in geographic HCI. Doing so is the goal of this special interest group meeting.

We broadly define geographic HCI research as work within $\mathrm{HCI}$ and related fields that takes a geographic approach. This approach can appear in any stage of the research, from central questions to important use cases. "Geographic" usually refers to processes that occur on or near the Earth's surface over any time period [4], but is typically limited to processes that vary over scales greater than a meter or so.

\section{The rise of geographic $\mathrm{HCI}$}

Three major advances in the past decade and a half have enabled the practice and study of geographic HCI. First, the public availability of GPS has made the process of locating an entity on the Earth's surface easy, cheap, and automated $[3,8]$. Second, simple UIs to geographic technology such as Google Earth and Bing Maps (and their APIs which let people easily create and share geographic information and tools to do so) have changed the face of geographic data dissemination [3]. Finally, the acquisition of geographic data has been drastically altered by the onset of the user-generated content (UGC) phenomenon [3]. Members of the HCI community from a variety of backgrounds have extensively leveraged each of these advances. They have also encouraged researchers in other areas of computing to explore HCI-related topics such as geographic social networks (e.g. [1]) and geography-related online user behavior (e.g. [2])

The possibility of a thorough literature review will be discussed as one option for the future at the SIG. For illustrative purposes, we present below a very small selection of geographic $\mathrm{HCI}$ research, biased towards the authors' own work in lieu of a specific section of this proposal dedicated to our biographies.

In natural user interfaces, Schöning et al. [15] designed a multi-touch virtual globe to better facilitate tasks that require true spatial thinking. The use of augmented reality in a geographic context is also very popular, dating back to Reitmayr et al.'s "Augmented Maps" system [13].

Mobile computing has seen an explosion of geographic HCI work. For instance, the Photomap project [14] allows users to leverage the cartographic benefits of large-scale public city maps on their mobile phone.

Social computing researchers have contributed significantly to the geographic HCI space. Priedhorsky et al. refined the idea of the geowiki $[11,12]$. Hecht and Gergle questioned the extent to which geographic UGC 
is truly "local" [7] and showed that "self-focus" can heavily bias geographic UGC [6].

In the social network space, Neustaedter et al. studied the groupware used by geocachers [10]. Backstrom et al. [1] and Cheng et al. [2] used human spatial behavior to perform location inference.

\section{New advances yield research opportunities}

Geographic HCI is rife with future research

opportunities. Goodchild, a prominent geographer, has speculated about four key near-term future developments in geotechnology, each of which has significant HCI implications [3]:

- Position acquisition technology will continue to increase in quality; we must consider a world in which "we know where everything is at all times".

- Indoor and 3D positioning technology will improve, which could open up as many new application spaces as GPS did.

- UGC will become more important to geographic information acquisition in fields ranging from the sciences to engineering to the military.

- Virtual globes (e.g. Google Earth) will be used as a platform to communicate not only the world as it is, but the world as it will, could, or should be.

\section{Exchange with the discipline of geography}

In the extensive geographic HCI literature, the number of citations to academic geography can likely be counted on two hands (plus perhaps two feet). This lack of communication with geography is a significant and growing problem because geographers have been considering for decades (and sometimes centuries), many of the same problems that HCI researchers are just now encountering. For example, geographers have studied distance's effect on spatial interaction for years and years (e.g., gravity models). Similarly, the decades-old framework of time geography [5] is extremely helpful in analyses of social networks (e.g., [9]). Moreover, an entire branch of geography is dedicated to the science and technology of geographic information.

Of course, the lack of communication is a two-way street. Geographers often do not incorporate our large body of knowledge into their work. At the SIG, we will discuss entry points to academic geography, as well as ways to increase our dialogue with the field. We will also invite targeted and local geographers to attend the conference and participate in the discussion.

\section{Plan for the SIG Meeting}

We will spend the first half to two-thirds of the session brainstorming about the current state of geographic $\mathrm{HCI}$. Our goal will be to sketch the broad outlines of where in HCI geography is being used, who is using it, how it is being used, and how it should be used. A key question we will start to answer is, "When is geography useful for HCI, and when it is not?" We hope this discussion will begin a dialogue among those who practice geographic HCI. The stage for this portion of the SIG will be set with a brief presentation by the organizers. 
The second stage of the meeting will discuss our options for building a "geographic $\mathrm{HCI}^{\text {" community and }}$ better connecting this community to the discipline of geography. The authors of this SIG are contemplating options including a workshop at a future conference, a journal special issue, and a survey paper on geographic $\mathrm{HCI}$. For each, a high priority is drawing contributions and discussion from both $\mathrm{HCI}$ and geography. In addition, we hope to recruit volunteers to help out with any of these community-building activities.

\section{Acknowledgements}

We thank Elisabeth Sedano and Martin Raubal for their help in shaping ideas.

\section{References}

[1] Backstrom, L., Sun, E., and Marlow, C. Find Me If You Can: Improving Geographical Prediction with Social and Spatial Proximity. WWW' 10.

[2] Cheng, Z., Caverlee, J., and Lee, K. You Are Where You Tweet: A Content-Based Approach to Geo-locating Twitter Users. CIKM '10.

[3] Goodchild, M.F. Geographic information systems: today and tomorrow. Annals of GIS 15, 1 (2009), 3-9.

[4] Goodchild, M. A Geographer Looks at Spatial Information Theory. COSIT '01: Conference on Spatial Information Theory 2001.

[5] Hägerstrand, T. What about people in Regional Science? Papers in Regional Science 24, 1970, 6-21.
[6] Hecht, B. and Gergle, D. Measuring Self-Focus Bias in Community-Maintained Knowledge Repositories.

Communities and Technologies 2009.

[7] Hecht, B. and Gergle, D. On The "Localness" of User-Generated Content. CSCW '10.

[8] Kennedy, M. The global positioning system and GIS: an introduction. Taylor and Francis, New York, 2002.

[9] Kostakos, V., O'Neill, E., Penn, A., Roussos, G., and Papadongongas, D. Brief Encounters: Sensing,

Modeling and Visualizing Urban Mobility and

Copresence Networks. ACM Transactions on ComputerHuman Interaction 17, 1 (2010), 2:1 - 2:38.

[10] Neutstaedter, C., Tang, A., and Judge, T. The Role of Community and Groupware in Geocache Creation and Maintenance. $\mathrm{CHI}$ ' 10.

[11] Priedhorsky, R., Masli, M., and Terveen, L. Eliciting and Focusing Geographic Volunteer Work. CSCW '10.

[12] Priedhorsky, R. and Terveen, L. The Computational Geowiki: What, Why, and How. CSCW '08.

[13] Reitmayer, G., Eade, E., and Drummond, T.

Localisation and Interaction for Augmented Maps. IEEE ISMAR '05.

[14] Schöning, J., Cheverst, K., Löchtefeld, M., Krüger, A., Rohs, M., and Taher, F. PhotoMap: Using Spontaneously taken Images of Public Maps for Pedestrian Navigation Tasks on Mobile Devices. Mobile HCI '09.

[15] Schöning, J., Hecht, B., Raubal, M., Krüger, A., Marsh, M., and Rohs, M. Improving Interaction with Virtual Globes through Spatial Thinking: Helping Users Ask "Why?". IUI '08. 